\title{
Clinical Effect of End-range Maitland Mobilization in the Management of Knee Osteoarthritis - A Pilot Study
}

\author{
MIKLÓS POZSGAI ${ }^{1,2}$, ERZSÉBET KÖVESDI ${ }^{3}$, BALÁZS NÉMETH ${ }^{4}$, ISTVÁN KISS ${ }^{4}$, \\ NELLI FARKAS ${ }^{5}$, TAMÁS ATLASZ ${ }^{6}$, MÁRK VÁCZI $^{6^{*}}$ and NÓRA NUSSER ${ }^{1,2^{*}}$ \\ ${ }^{1}$ Harkány Thermal Rehabilitation Centre, Harkány, Hungary; \\ ${ }^{2}$ Medical School, University of Pécs, Pécs, Hungary; \\ ${ }^{3}$ Institute of Physiology, Medical School, University of Pécs, Pécs, Hungary; \\ ${ }^{4}$ Department of Public Health Medicine, Medical School, University of Pécs, Pécs, Hungary; \\ ${ }^{5}$ Institute of Bioanalysis, Medical School, University of Pécs, Pécs, Hungary; \\ ${ }^{6}$ Institute of Sport Sciences and Physical Education, University of Pécs, Pécs, Hungary
}

\begin{abstract}
Background/Aim: Different manual therapy techniques and conservative therapy have been used separately for alleviation of pain and improvement of physical function in patients with knee osteoarthritis (KOA). However, no study has reported the effect of combination of these treatment modalities in the management of KOA. Our aim was to test the feasibility of the study design and to compare the effect of end-range Maitland mobilization to conservative therapy in KOA. Patients and Methods: Fifteen patients (conservative therapy group: $C G$ ) received conservative therapy alone, fifteen patients (Maitland plus conservative therapy group: $M+C G$ ) received additionally end-range Maitland mobilization during the 3-week study period. Outcomes were pain intensity, measured with visual analogue scale (VAS) in general and during functional activities, passive range of motion (PROM) and peak muscle force during knee flexion and extension, Timed Up and Go test and 6-Minute Walk Test (6MWT). Results: All outcomes improved significantly in both groups. Magnitude of changes was significantly greater in $M+C G$ compared to $C G$ regarding all VAS pain scores, flexion PROM of both knees, right hamstring peak muscle force and 6MWT. Conclusion: With few modifications, this study design seems feasible for
\end{abstract}

This article is freely accessible online.

*These Authors contributed equally to this work.

Correspondence to: Miklós Pozsgai, Harkány Thermal Rehabilitation Centre, Zsigmondy walkway 1, 7815 Harkány, Baranya, Hungary. Tel: +36 72580900/849, e-mail: pozsgay.miklos@harkanykorhaz.hu

Key Words: Knee osteoarthritis, Maitland manual therapy, conservative therapy, rehabilitation. the comparison of end-range Maitland mobilization with conservative therapy in KOA. Moreover, end-range Maitland mobilization in addition to conservative therapy appeared more effective in relief of pain and improvement of functional status than conservative therapy alone in KOA.

Knee osteoarthritis (KOA) is a musculoskeletal condition affecting mostly older people. Main symptoms in KOA are pain, stiffness, crepitation, instability, loss of range of motion and limited physical activity (1). The prevalence of KOA has been reported appearing in $13 \%$ and $10 \%$ of women and men, respectively, aged 60 years or above (2).

Different international guidelines highly recommend conservative therapy including land- and water-based exercises, electrotherapy $(3,4)$ and medical bath (4) for the management of KOA. The effectiveness of these interventions has been widely demonstrated in KOA (5-13); however, applying medical bath depends mainly on geographical accessibility. Nevertheless, in a possibility of using medical bath, just as in Hungary, the effectiveness on alleviation of pain and improvement of physical function has been reported in $\operatorname{KOA}(13,14)$. Additionally, as 3-week inpatient rehabilitation care has been reported to be more efficient in the treatment of symptoms and functional deficits in KOA compared to outpatient rehabilitation (15), applying land- and water-based exercises, electrotherapy and medical bath combined in 3-week inpatient rehabilitation care could produce positive effects in the management of KOA.

Maitland manual therapy out of different manual therapies could be a useful adjunct intervention (3) in the management of symptoms in KOA. Maitland manual therapy applies both accessory and physiological technique and varies the performed Grades from I to IV. Grade I, applied with accessory technique, and Grade II, applied with accessory or physiological technique, are used in pain-free position for 


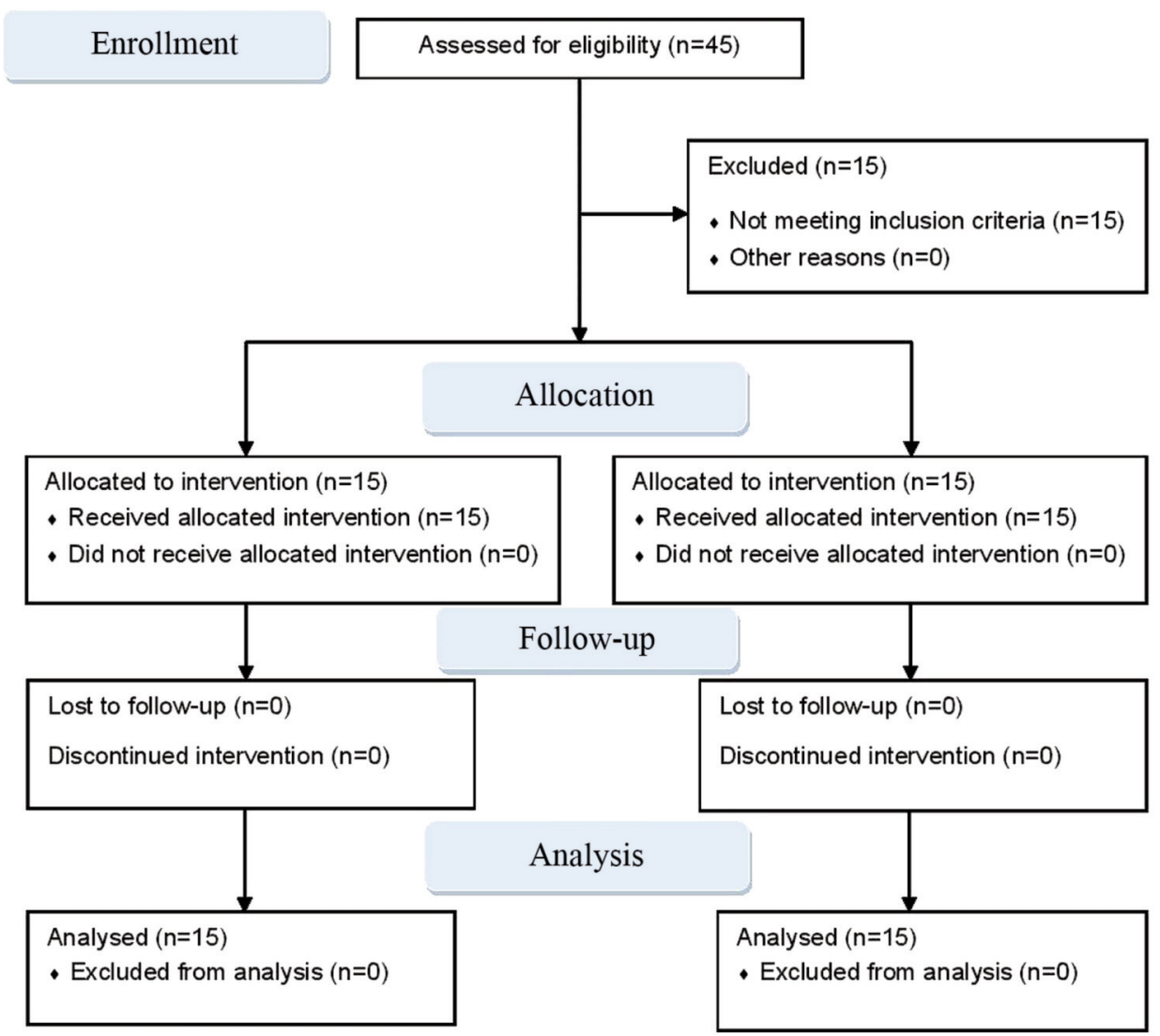

Figure 1. Flow diagram of the trial.

alleviating severe pain only. Grades III and IV are applied with both accessory or physiological technique and are performed in end-range in order to restore full range of motion (16). Positive effects of Maitland manual therapy have been proven in $\operatorname{KOA}(17,18)$; however, knee joints were neither mobilized in end-range positions, nor managed in addition with conservative therapy in those studies. Previous studies showed that land-based exercises combined with different manual therapies are more effective than land-based exercises alone in KOA $(19,20)$. Therefore, the combination of end-range Maitland mobilization with these interventions might also improve the functional status of the arthritic knee. Although all end-range mobilizations of the different manual therapies provide the same similar stretching effect, only end-range Maitland mobilization applies two Grades in resistance without active movement of the patient. Thus, the mobilization-induced hypoalgesic and functional effects observed in the management of other joints' condition (21-23) could provide superior effects in addition to conservative therapy in KOA as well.

Therefore, the aim of this pilot study was to test the feasibility of the study design and to investigate the effect of end-range Maitland mobilization in combination with conservative therapy in a 3-week inpatient rehabilitation care on alleviation of pain, compared to conservative therapy alone, in KOA patients. Furthermore, different function-related measures were also evaluated regarding potential effects.

\section{Patients and Methods}

Study design. Assessor-blinded, non-randomized interventional trial was conducted between March and September 2018. All patients participated in the trial were admitted for 3-week inpatient rehabilitation care to Harkány Thermal Rehabilitation Centre between June 2017 and July 2018. Patients screened self-selected eligible for participation in the trial were enrolled and allocated to Maitland plus conservative therapy group $(\mathrm{M}+\mathrm{CG})$ and Conservative therapy group (CG). Two different investigators carried out all tests (MP) in a physical therapy room at the Balneology Department and assessed all variables (NN) at baseline (day 0) and after 3-week treatment period at follow-up (day 21), respectively. The trial was approved by the Regional Research Ethics Committee of the Medical Center in Pécs (7144 - PTE 2018). Due the first clinical trial conducted in the hospital and therefore questionability of implementation of the study, the trial was registered retrospectively on ClinicalTrials.gov (identifier number: NCT04270253). The flow diagram of the trial is displayed in Figure 1. 
Patients. Inclusion criteria of patients were the clinical classification criteria of KOA according to the American College of Rheumatology $(24,25)$, categorization of End of Range Problem based on Maitland's classification, age above 65 years, at least half year existing and at least 3 pain scores measured with Visual Analogue Scale (VAS) during weight-bearing activities, bilateral, moderate-to-severe symptomatic tibiofemoral KOA with radiographic evidence, at least $90^{\circ}$ passive knee flexion range and sufficient mental status. Exclusion criteria were acute inflammation of the knee, intraarticular injections within the last 3 months, total knee replacement in the opposite side, class II obesity (body mass index, BMI $>35 \mathrm{~kg} / \mathrm{m}^{2}$ ), severe degenerative lumbar spine disease (e.g. spondylolisthesis), systemic inflammatory arthritic or neurological condition, conservative intervention attendance within 6 months, contraindication to conservative therapy and manual therapy, unstable heart condition or complex regional pain syndrome. Written informed consent was obtained from all patients.

Conservative therapy. Conservative therapy for patients in both groups including medical bath, water- and land-based exercises and TENS therapy was delivered in the Department of Balneology. Medical bath and water-based exercises were carried out for $20 \mathrm{~min}$ in a total of 15 sessions over the 3-week treatment period, respectively. Medical bath was delivered in carbonyl sulfide containing medical water heated at $34^{\circ} \mathrm{C}$. Water-based exercises were applied in the same water heated at $32^{\circ} \mathrm{C}$. Land-based exercises and TENS therapy (Tensel Double Smart, Minel Elektronikai Kft, Budapest, Hungary, applied strength between 15-25 mA) were applied 3-times per week for 20 min during the 3-week treatment period. Water-based exercises included dynamic movements of upper and lower limb, isotonic strengthening exercises of muscles around the spine and peripheral joints, exercises for improving balance and coordination. Land-based exercises consisted of exercises improving knee joint range of motion, isotonic strengthening and static stretching exercises for the quadriceps, hamstring and gastrocnemiussoleus muscles. All types of conservative therapy except TENS therapy were delivered as group therapy under supervision of a trained and experienced physiotherapist.

Maitland manual therapy. Patients in $\mathrm{M}+\mathrm{CG}$ received in addition oscillatory Grade III or IV end-range Maitland mobilization. The different Grades were applied depending on the level of tolerance and pain of each patient (26). Patients laid down on a plinth supine with the knee joint positioned in its actual end-range. Flexion endrange of tibiofemoral joint was mobilized with accessory technique, which either reproduced the knee pain or was the most limited in flexion end-range. Extension end-range of tibiofemoral joint was mobilized with physiological extension technique due performing accessory technique in extension end-range is difficult and strengthdemanding. Flexion and extension end-range of patellofemoral joint was mobilized with accessory, longitudinal caudal and cranial technique of the patella following the physiological movement of the patella, respectively. The applied manual contact precisely reproduced the hand positioning of the mobilization by movement of the therapist's body without applying any other movement in all cases. All mobilizations were performed as described by Maitland (16). Both knees were mobilized in every session. All mobilizations were repeated twice at the rate of one oscillation per second for 2 min in each session, twice a week, 6 times in total during the 3week treatment period. Mobilizations were performed individually in a physical therapy room of the Department of Balneology after the daily conservative intervention with a 20 -sec break between each mobilization by a classified Maitland manual therapist (MP). Neither during the 3-week treatment period, nor after the applied mobilizations were confounding factors or adverse events observed resulting in exacerbation of symptoms and consequently in patient drop out.

Outcome measures. Pain: Perceived pain intensity was evaluated using VAS on a $0-10 \mathrm{~mm}$ line, with 0 being no pain and 10 being as worst imaginable pain (27). Patients were instructed to rate their average level of pain in general (VAS 1), during getting up from a chair (VAS 2), during getting in car (VAS 3), during turning while walking (VAS 4) and during stair descending (VAS 5).

Passive range of motion (PROM): Flexion and extension passive range of motion (PROM) of knee joints were measured bilaterally with the full-circle $1^{\circ}$-increment plastic standard long-arm extendable goniometer (Elite Medical Instruments, USA) with a moveable arm (28). Flexion PROM and extension PROM was measured in prone and supine position, respectively, with the patient lying comfortably on the plinth (29). Onset of pain determined end-range in both measurements. Every test was performed 3-times.

Peak muscle force: Peak voluntary isometric muscle force of quadriceps and hamstring muscles were evaluated in both legs using CITEC hand-held dynamometer (CIT Technics, Haren, The Netherlands) (30). Patients were in sitting position with $90^{\circ}$ hip and knee flexion. The dynamometer was placed on the tibia at $30 \mathrm{~cm}$ distally from the knee joint line over the anterior and posterior surface. Patients were instructed to exert maximal force by pushing the shin against the dynamometer. Verbal encouragement was given to patients during each contraction. With $30 \mathrm{~s}$ rest interval for avoiding muscle fatigue, three consecutive contractions of 3-5 sec were recorded in Newton $(\mathrm{N})$ for each muscle group.

Functional performance: Timed Up and Go Test (TUG) and 6Minute Walk Test (6MWT) were used to evaluate patients' functional performance. TUG is a standardized test, according to which patients were instructed to rise from a standard armchair, walk to a point on the floor 3 meters away, return to the chair, and sit down while being timed in sec with a stopwatch. Patients performed this test in their own pace (31). During the 6MWT, patients were instructed to walk as far as possible for 6 min on a 50 $\mathrm{m}$ long corridor back and forth. The total distance covered in meters was measured (32).

Statistical analysis. Shapiro-Wilk test was conducted to examine distribution of the measured variables. Considering results of the normality tests, independent samples $t$-test was used to assess difference in the demographical data and baseline values between the groups, such as age, height, weight, BMI, duration of symptoms, all PROM and peak muscle force variables; Mann-Whitney $U$-test was used to calculate baseline differences between groups in all other variables. The differences between post- and pre- treatment values were examined with paired sample $t$-test or Wilcoxon-test and the magnitudes of changes were expressed in percentage. These percentages were then compared between groups using independent sample $t$-test or Mann-Whitney $U$-test, depending on the distribution of the variable. All calculations were carried out and analyzed with IBM SPSS Statistics 25.0 (IBM Corp., USA). Results are presented in median with 25 and 75 percentiles and the percentage 
Table I. Demographic characteristics of patients.

\begin{tabular}{lccc}
\hline Characteristics & $\begin{array}{c}\mathrm{M}+\mathrm{CG}(\mathrm{n}=15) \\
\mathrm{n}\end{array}$ & $\begin{array}{c}\mathrm{CG}(\mathrm{n}=15) \\
\mathrm{n}\end{array}$ & $p$-Value \\
\hline Age* (years) & $66.26 \pm 8.73$ & $70.27 \pm 4.92$ & 0.220 \\
Gender (female/male) & $9 / 6$ & $8 / 7$ & \\
Body height* $(\mathrm{m})$ & $166.6 \pm 9.02$ & $162.2 \pm 9.06$ & 0.226 \\
Body weight* $(\mathrm{kg})$ & $83.07 \pm 17.0$ & $82.4 \pm 13.60$ & 0.546 \\
BMI* $\left(\mathrm{kg} / \mathrm{m}^{2}\right)$ & $29.73 \pm 4.69$ & $31.16 \pm 3.52$ & 0.504 \\
Dominant side (left/right) & $8 / 7$ & $8 / 7$ & \\
Comorbidity & & & \\
Heart condition & 10 & 7 & \\
Respiratory condition & 1 & 2 & \\
Lumbar disc herniation & 4 & 2 & \\
$\quad$ Other diseases & 13 & 12 & \\
Time from onset & $11.5 \pm 12.20$ & $8.47 \pm 5.21$ & 0.775 \\
of symptoms* (years) & & & \\
More affected side & $9 / 6$ & $8 / 7$ & \\
(left/right) & & & \\
Location of knee pain & & & \\
$\quad$ Medial & 7 & 5 & \\
Lateral & 3 & 3 & \\
Anterior joint line & 12 & 13 & \\
$\quad$ Posterior joint line & 1 & 1 & \\
Walking aids & 3 & 2 & \\
& & &
\end{tabular}

*Data are mean \pm standard deviation. $\mathrm{M}+\mathrm{CG}$, Maitland plus conservative intervention group; CG, conservative therapy group; BMI, body mass index. Patients had more comorbidities and presented location of knee pain in many areas.

change in mean with standard deviation (SD). All $p$-values equal or below 0.05 were considered statistically significant.

\section{Results}

Thirty patients ( 17 women, 13 men, mean age $=68.63 \pm 8.34$ years) were found eligible and participated in the trial. All involved patients completed follow-up and were analysed. No significant differences were found in baseline characteristics between both groups (Table I). No significant differences were found in any outcome parameters between both groups at baseline, except the greater right hamstring peak muscle force in $\mathrm{M}+\mathrm{CG}(p<0.001)$ (Table II).

Pain. All post-treatment VAS pain scores reduced significantly in both groups compared to the pre-treatment scores. Moreover, the magnitude of these reductions was significantly greater in the $\mathrm{M}+\mathrm{CG}$ compared to the $\mathrm{CG}$ group (VAS 1: $42.78 \%, p=0.002$; VAS 2: $40.67 \%, p<0.001$; VAS 3: $35.84 \%, p=0.004$; VAS $4: 35.43 \%, p=0.008$; VAS $5: 31.02 \%$, $p=0.004)$ (Table III).

PROM. Flexion and extension PROM improved significantly in both groups compared to the pre-treatment scores. Furthermore, the magnitude of improvement of flexion
PROM of both knees was significantly greater in the $\mathrm{M}+\mathrm{CG}$ compared to the CG group (right side: $14.66 \%, p=0.01$; left side: $15.35 \%, p<0.001)$ (Table III).

Peak muscle force. All peak muscle force values increased significantly in both groups after treatment, compared to pretreatment scores. Moreover, the magnitude of improvement of right hamstring peak muscle force was significantly greater in the $\mathrm{M}+\mathrm{CG}$ compared to the CG group $(32.26 \%$, $p=0.045$ ) (Table III).

Physical performance. TUG decreased and 6MWT improved significantly in both groups compared to the pre-treatment scores. Furthermore, the magnitude of improvement of 6MWT was significantly greater in $\mathrm{M}+\mathrm{CG}$ compared to $\mathrm{CG}$ $(31.45 \%, p<0.001)$ (Table III).

\section{Discussion}

The greater reduction of general VAS pain score in $\mathrm{M}+\mathrm{CG}$ suggests the additional hypoalgesic effect of end-range Maitland mobilization attributed to multiple neurophysiological mechanisms (33, 34) and stretching of the tightened periarticular tissues (35-37). Azlin et al. showed the positive effect of Maitland mobilization in addition to different landbased exercises followed by thermal therapy against different land-based exercises and thermal therapy alone on reduction of general pain. However, this trial studied a 4-week-long treatment period (17). In contrast, Rao et al. reported alleviation of pain immediately following the Maitland mobilization in KOA patients (18). However, the more non-noxious input and consequently the hypoalgesic effect of all of the performed Grades with different techniques could have contributed to the rapid alleviation of pain in that trial. The functional activities are often reported as painful everyday movements and pain is indirectly related to the functional status in KOA. Our results, compared to previous research, indicate greater hypoalgesic effect of end-range Maitland mobilization due to effects discussed previously regarding general pain. Direct comparison cannot be made regarding pain intensity during certain functional activities, because they were not investigated in earlier trials. However, these findings might serve as an important measurement that could be used in future trials.

The greater change of flexion PROM in $\mathrm{M}+\mathrm{CG}$ can be attributed to the improved extensibility of the tightened periarticular tissues as a result of end-range Maitland mobilization (16). This finding corroborates previous studies regarding improvement of PROM of different joints' (21-23). However, neither conservative therapy, nor 3-week treatment period was applied in addition in any of these trials. Some explanations for the improvement of flexion PROM in M+CG: firstly, end-range accessory movement increases the arthrokinematic movement of the joint in contrast to end-range 
Table II. Pre- and post- treatment results of PROM, peak muscle force, TUG and 6MWT.

\begin{tabular}{|c|c|c|c|c|c|c|c|c|c|}
\hline \multirow[t]{2}{*}{ Variables } & \multicolumn{4}{|c|}{$\mathrm{M}+\mathrm{CG}$} & \multicolumn{4}{|c|}{ CG } & \multirow{2}{*}{$\begin{array}{c}\begin{array}{c}\text { Between- } \\
\text { group } \\
\text { comparison }\end{array} \\
p \text {-Value }\end{array}$} \\
\hline & Pre & Post & $\begin{array}{l}\text { Percentage } \\
\text { change }(\%)\end{array}$ & $p$-Value & Pre & Post & $\begin{array}{l}\text { Percentage } \\
\text { change }(\%)\end{array}$ & $p$-Value & \\
\hline \multicolumn{10}{|l|}{ PROM (degree) } \\
\hline \multicolumn{10}{|l|}{ Flexion } \\
\hline Right side & 107 (96-116) & $116(110-136)$ & $19.78(18.65)$ & 0.002 & 97 (90-104) & $104(90-107)$ & $5.12(5.09)$ & 0.002 & 0.01 \\
\hline Left side & $110(90-118)$ & $120(114-134)$ & $19.39(14.85)$ & $<0.001$ & $104(96-115)$ & $107(100-118)$ & $4.04(3.15)$ & 0.002 & $<0.001$ \\
\hline \multicolumn{10}{|l|}{ Extension } \\
\hline Right side & $-4(-6--1)$ & $-1(-4-0)$ & $45.44(44.30)$ & 0.007 & $-5(-6--2)$ & $-4(-6-0)$ & $18.99(35.76)$ & 0.039 & 0.087 \\
\hline Left side & $-4(-7--2)$ & $-2(-4-0)$ & $38.08(42.72)$ & 0.011 & $-4(-6--3)$ & $-4(-5--1)$ & $19.52(35.71)$ & 0.039 & 0.174 \\
\hline \multicolumn{10}{|l|}{$\begin{array}{l}\text { Peak muscle } \\
\text { force }(\mathrm{N})\end{array}$} \\
\hline \multicolumn{10}{|c|}{ Hamstring } \\
\hline Right side ${ }^{\wedge}$ & $99.4(53.4-113)$ & $155(128-202.6)$ & $43.73(50.26)$ & $<0.001$ & $76.7(67.7-104)$ & $84.7(77.4-110)$ & $11.47(7.29)$ & $<0.001$ & 0.045 \\
\hline Left side & $88.4(45-106)$ & $114.4(98-126)$ & $72.03(83.03)$ & $<0.001$ & $78.8(67.8-111)$ & $89.6(80.4-128)$ & $13.94(6.32)$ & $<0.001$ & 0.089 \\
\hline \multicolumn{10}{|l|}{ Quadriceps } \\
\hline Right side & $\begin{array}{c}131.6 \\
(95-185.4)\end{array}$ & $\begin{array}{c}155 \\
(128-202.6)\end{array}$ & $35.12(65.68)$ & $<0.001$ & $102(89.5-148)$ & $\begin{array}{c}118.6 \\
(107-187.5)\end{array}$ & $25.27(17.34)$ & $<0.001$ & 0.436 \\
\hline Left side & $\begin{array}{c}127.8 \\
(61.4-156.4)\end{array}$ & $165(136-198)$ & $74.28(106.71)$ & $<0.001$ & $122(92-146)$ & $145(114-195)$ & $26.27(22.40)$ & $<0.001$ & 0.486 \\
\hline TUG (s) & $\begin{array}{c}13.78 \\
(11.44-17.71)\end{array}$ & $11.49(9.58-12.8)$ & $19.99(12.95)$ & $<0.001$ & $\begin{array}{c}12.86 \\
(11-16.66)\end{array}$ & $\begin{array}{c}11.74 \\
(9.91-14.57)\end{array}$ & $10.78(10.08)$ & $<0.001$ & 0.081 \\
\hline 6MWT (m) & $388(288-465)$ & $450(358-601)$ & $36.33(51.98)$ & $<0.001$ & $371(286-381)$ & $376(299-407)$ & $4.88(6.24)$ & $<0.001$ & $<0.001$ \\
\hline
\end{tabular}

Values represent median with 25 and 75 percentiles and percentage change is presented as mean \pm standard deviation. M+CG, Maitland plus conservative therapy group; CG, conservative therapy group; PROM, passive range of motion; N, Newton; TUG, timed up and go test; 6MWT, 6-minute walk test. ${ }^{\wedge}$ Significant baseline difference between $\mathrm{M}+\mathrm{CG}$ and CG.

physiological movement, which is required for achieving full passive and subsequently active range of motion. Direction and type of end-range accessory mobilization is determined in Mulligan manual therapy (38), while only the direction of endrange accessory mobilization is determined in Maitland manual therapy. Therefore, the applied end-range accessory Maitland mobilization might be able to improve the arthrokinematic movement of the mobilized joint as well, independently from its type, and should be applied primarily as suggested by Maitland et al. (16). Secondly, the improvement of extension against flexion PROM, in general, demands more time in clinical practice. One explanation for this may be attributed to the increasing tissue resistance whilst approaching end-range of extension PROM due to the screw-home mechanism. Therefore, improvement of extension PROM in both groups may be attributed to the improvement of elasticity of connective tissues by conservative therapy $(3,4)$. Although mobilization of patellofemoral joint with end-range accessory technique in addition to land-based exercises increase extension PROM in patients with patellofemoral pain syndrome (39), mobilization of tibiofemoral joint with accessory technique may produce greater effect on improvement of extension PROM instead of physiological technique in KOA.
The greater improvement of right hamstring peak muscle force in $\mathrm{M}+\mathrm{CG}$ can be attributed to the arthrokinetic reflex. Page et al. suggested that a dysfunctional joint causes a secondary inhibition of muscle activation via anterior horn motor cells leading to decreased muscle force (40). Arthrokinetic reflex activated by mobilization through stimulation of joint mechanoreceptors can inhibit this mechanism and therefore increases motor unit activity $(41,42)$; however, only in the less painful side of bilateral KOA, based on our present result. As previous data on the effect of end-range mobilization on peak muscle force are inconsistent $(43,44)$, the observed improvement of peak force of both quadriceps and left hamstring muscles in both groups is considered primarily due to the effect of land-, and water-based exercises $(3,4)$. The inappropriate stimulation of mechanoreceptors might be attributed to either the high age of patients or the severity of KOA. Reinke et al. showed that stimulation of the peripheral cutaneous mechanoreceptors is not age-related in rats (45). Although no data are available for humans, there may be differences in the stimulations of mechanoreceptors according to age or degree of joint damage. Furthermore, the correspondence between severity of KOA and stimulation of mechanoreceptors is unclear. Thus, further trials might be needed to clarify this relationship. 
in vivo $35: 1661-1668(2021)$

Table III. Pre-, and post- treatment results of the different visual analogue scale (VAS) pain scores.

\begin{tabular}{|c|c|c|c|c|c|c|c|c|c|}
\hline \multirow[t]{2}{*}{ VAS scores } & \multicolumn{4}{|c|}{$\mathrm{M}+\mathrm{CG}$} & \multicolumn{4}{|c|}{ CG } & \multirow{2}{*}{$\begin{array}{c}\begin{array}{c}\text { Between- } \\
\text { group } \\
\text { comparison }\end{array} \\
p \text {-Value }\end{array}$} \\
\hline & Pre & Post & $\begin{array}{l}\text { Percentage } \\
\text { change }(\%)\end{array}$ & $p$-Value & Pre & Post & $\begin{array}{l}\text { Percentage } \\
\text { change }(\%)\end{array}$ & $p$-Value & \\
\hline VAS 1 & $6(5-8)$ & $3(0-5)$ & $65.25(30.44)$ & $<0.001$ & $6(5-7)$ & $4(3-5)$ & $22.97(24.44)$ & 0.007 & 0.002 \\
\hline VAS 2 & $7(6-8)$ & $2(0-4)$ & $65.85(33.76)$ & $<0.001$ & $6(4-6)$ & $4(3-6)$ & $25.18(26.90)$ & 0.003 & $<0.001$ \\
\hline VAS 3 & $6(5-8)$ & $2(0-5)$ & $60.70(35.85)$ & $<0.001$ & $6(5-6)$ & $4(3-5)$ & $24.86(22.12)$ & 0.004 & 0.004 \\
\hline VAS 4 & $6(2-7)$ & $1(0-3)$ & $67.48(36.72)$ & $<0.001$ & $4(3-5)$ & $3(2-4)$ & $32.05(29.82)$ & 0.004 & 0.008 \\
\hline VAS 5 & $7(5-8)$ & $2(1-5)$ & $58.20(31.35)$ & $<0.001$ & $7(5-8)$ & $4(3-7)$ & $27.18(23.57)$ & 0.005 & 0.004 \\
\hline
\end{tabular}

Values represent median with 25 and 75 percentiles and the percentage change is presented as mean \pm standard deviation. M+CG, Maitland plus conservative therapy group; CG, conservative therapy group; VAS 1, general pain; VAS 2, pain rising from a chair; VAS 3, pain getting in car; VAS 4, pain turning while walking; VAS 5, pain during stair descending.

The greater improvement regarding $6 \mathrm{MWT}$ in the $\mathrm{M}+\mathrm{CG}$ group indicates an additional effect of end-range Maitland mobilization on functional performance. Some possible explanations are proposed for this finding: firstly, patients in $\mathrm{M}+\mathrm{CG}$ experiencing greater alleviation of pain could have led to putting greater load on their knees and walk consequently longer distance during 6-minute walk. Secondly, knee flexion PROM depends on the elasticity of both the vasti and the rectus femoris muscle. The elasticity of rectus femoris muscle, however, also influences hip extension, which is an important contributor to stride length during gait $(46,47)$. Therefore, the greater increase of flexion PROM and right hamstring peak muscle force together might have contributed to the improved walking distance in $\mathrm{M}+\mathrm{CG}$. Our result corroborates previous finding of Kappetijn et al. concerning 6MWT (44); however, in that study, end-range Maitland mobilization was performed in the first 12 sessions of an 8-week treatment program, along with land-based knee exercises. Regarding the TUG test in the present trial, the decrease of time in both groups might be attributed to the cumulative effect of conservative therapy on all measured physical parameters $(3,4)$; however, not likely attributed to alleviation of pain. Contrary to our suggestion, Rao et al. reported an immediate decrease of TUG time after performing different Grades of both Maitland mobilization techniques without addition of conservative therapy, in contrast to the present result (18); however, patients with mild-to-moderate severity of $\mathrm{KOA}$ were mobilized in that trial, in contrast to patients presenting moderate-to-severe severity of KOA in the present trial. Therefore, the impact of end-range Maitland mobilization on dynamic balance may depend on the severity of KOA independently from alleviation of pain. Future studies should focus on clarification of this supposition.

Some limitations should be highlighted. Patients in $\mathrm{M}+\mathrm{CG}$ were not blinded and patients in $\mathrm{CG}$ were not receiving sham intervention. Therefore, the improved performance in $\mathrm{M}+\mathrm{CG}$, mainly in determination of pain, may be attributed to awareness of patients receiving Maitland manual therapy. Therefore, performance bias could be present. Furthermore, the small sample size may limit the generalizability of the present results. Additionally, the present trial focused especially on the effect of mobilization of the tibiofemoral and patellofemoral joints, despite examination and mobilization of the adjacent joints near the knee joint is recommended based on Maitland manual therapy.

\section{Conclusion}

This study design is capable of investigating the effect of end-range Maitland mobilization in addition to conservative therapy, in a 3-week inpatient rehabilitation care, on KOA. In this pilot study, both interventions (CG and $\mathrm{M}+\mathrm{CG}$ ) were effective in alleviation of pain and improvement of physical function in KOA. However, oscillatory Grade III or IV endrange Maitland mobilization in addition to conservative therapy provided superior effect on alleviation of pain in general and during certain functional activities, on flexion PROM of both knees, on right hamstring peak muscle force and on 6MWT, compared to conservative therapy alone, in patients with moderate-to-severe KOA. Therefore, these outcome measures are good indicators for evaluating the effect of end-range Maitland mobilization. However, several modifications may be required in future studies to avoid performance bias mentioned earlier. Firstly, a multicenter interventional trial with bigger sample size should be performed. Secondly, patients should be blinded. For this reason, sham therapy should be performed in control group. Thirdly, the 3-week treatment period could be complemented by 3 -month follow-up. These changes together could lead to further information regarding both the short- and long-term effect and the superiority of end-range Maitland mobilization 
in KOA. As a consequence, the effectiveness and importance of end-range Maitland mobilization in addition to conservative therapy can be highlighted in KOA as well.

\section{Conflicts of Interest}

Authors declare that they have no conflicts of interest.

\section{Authors' Contributions}

Miklós Pozsgai acquisited and analysed data and drafted the article; Erzsébet Kövesdi recruited patients and drafted the article; Balázs Németh and István Kiss recruited patients; Nelli Farkas conducted the statistical analysis; Tamás Atlasz analysed data and drafted the article; Márk Váczi conducted the study design, drafted the article and approved the final version; Nóra Nusser recruited patients, conducted the study design, drafted the article and approved the final version.

\section{Acknowledgements}

The support of Harkány Thermal Rehabilitation Centre, University of Pécs as well as patients for their contributions is appreciated.

\section{References}

1 Spector TD and Hart DJ: How serious is knee osteoarthritis? Ann Rheum Dis 51(10): 1105-1106, 1992. PMID: 1444621. DOI: $10.1136 /$ ard .51 .10 .1105

2 Heidari B: Knee osteoarthritis prevalence, risk factors, pathogenesis and features: Part I. Caspian J Intern Med 2(2): 205-212, 2011. PMID: 24024017.

3 Hochberg MC, Altman RD, April KT, Benkhalti M, Guyatt G, McGowan J, Towheed T, Welch V, Wells G, Tugwell P and American College of Rheumatology: American College of Rheumatology 2012 recommendations for the use of nonpharmacologic and pharmacologic therapies in osteoarthritis of the hand, hip, and knee. Arthritis Care Res (Hoboken) 64(4): 465-474, 2012. PMID: 22563589. DOI: 10.1002/acr.21596

4 McAlindon TE, Bannuru RR, Sullivan MC, Arden NK, Berenbaum F, Bierma-Zeinstra SM, Hawker GA, Henrotin Y, Hunter DJ, Kawaguchi H, Kwoh K, Lohmander S, Rannou F, Roos EM and Underwood M: OARSI guidelines for the nonsurgical management of knee osteoarthritis. Osteoarthritis Cartilage 22(3): 363-388, 2014. PMID: 24462672. DOI: 10.1016/j.joca.2014.01.003

5 Fransen M, McConnell S, Harmer AR, Van der Esch M, Simic $\mathrm{M}$ and Bennell KL: Exercise for osteoarthritis of the knee. Cochrane Database Syst Rev 1: CD004376, 2015. PMID: 25569281. DOI: 10.1002/14651858.CD004376.pub3

6 Nguyen C, Lefèvre-Colau MM, Poiraudeau S and Rannou F: Rehabilitation (exercise and strength training) and osteoarthritis: A critical narrative review. Ann Phys Rehabil Med 59(3): 190195, 2016. PMID: 27155923. DOI: 10.1016/j.rehab.2016.02.010

7 Barker AL, Talevski J, Morello RT, Brand CA, Rahmann AE and Urquhart DM: Effectiveness of aquatic exercise for musculoskeletal conditions: A meta-analysis. Arch Phys Med Rehabil 95(9): 1776-1786, 2014. PMID: 24769068. DOI: 10.1016/j.apmr.2014.04.005
8 Waller B, Ogonowska-Slodownik A, Vitor M, Lambeck J, Daly D, Kujala UM and Heinonen A: Effect of therapeutic aquatic exercise on symptoms and function associated with lower limb osteoarthritis: systematic review with meta-analysis. Phys Ther 94(10): 13831395, 2014. PMID: 24903110. DOI: 10.2522/ptj.20130417

9 Brosseau L, Milne S, Robinson V, Marchand S, Shea B, Wells $\mathrm{G}$ and Tugwell P: Efficacy of the transcutaneous electrical nerve stimulation for the treatment of chronic low back pain: A metaanalysis. Spine (Phila Pa 1976) 27(6): 596-603, 2002. PMID: 11884907. DOI: 10.1097/00007632-200203150-00007

10 Chen LX, Zhou ZR, Li YL, Ning GZ, Li Y, Wang XB and Feng SQ: Transcutaneous electrical nerve stimulation in patients with knee osteoarthritis: Evidence from randomized-controlled trials. Clin J Pain 32(2): 146-154, 2016. PMID: 25803757. DOI: 10.1097/AJP.0000000000000233

11 Fioravanti A, Valenti M, Altobelli E, Di Orio F, Nappi G, Crisanti A, Cantarini L and Marcolongo R: Clinical efficacy and cost-effectiveness evidence of spa therapy in osteoarthritis. The results of "Naiade" Italian project. Panminerva Med 45(3): 211217, 2003. PMID: 14618120.

12 Verhagen AP, Cardoso JR and Bierma-Zeinstra SM: Aquatic exercise \& balneotherapy in musculoskeletal conditions. Best Pract Res Clin Rheumatol 26(3): 335-343, 2012. PMID: 22867930. DOI: 10.1016/j.berh.2012.05.008

13 Kulisch Á, Benkö Á, Bergmann A, Gyarmati N, Horváth H, Kránicz Á, Mándó ZS, Matán Á, Németh A, Szakál E, Szántó D, Szekeres L and Bender T: Evaluation of the effect of Lake Hévíz thermal mineral water in patients with osteoarthritis of the knee: A randomized, controlled, single-blind, follow-up study. Eur J Phys Rehabil Med 50(4): 373-381, 2014. PMID: 24594851.

14 Kovács I and Bender T: The therapeutic effects of Cserkeszölö thermal water in osteoarthritis of the knee: a double blind, controlled, follow-up study. Rheumatol Int 21(6): 218-221, 2002. PMID: 12036207. DOI: 10.1007/s00296-001-0167-6

15 Özkuk K, Uysal B, Ateş Z, Ökmen BM, Sezer R and Dilek G: The effects of inpatient versus outpatient spa therapy on pain, anxiety, and quality of life in elderly patients with generalized osteoarthritis: a pilot study. Int J Biometeorol 62(10): 1823-1832, 2018. PMID: 30022244. DOI: 10.1007/s00484-018-1584-5

16 Hengeveld E and Banks K: Maitland's Peripheral Manipulation. 4th edition, $2^{\text {nd }}$ volume. Oxford, Butterworth-Heinemann, pp. 20, 206, 500, 507-510, 517, 2005.

17 Nor Azlin MN and Lyn KS: Effects of passive joint mobilization on patients with knee osteoarthritis. Sains Malaysiana 40(12): 1461-1465, 2011.

18 Rao RV, Balthillaya G, Prabhu A and Kamath A: Immediate effects of maitland mobilization versus mulligan mobilization with movement in osteoarthritis knee- A randomized crossover trial. J Bodyw Mov Ther 22(3): 572-579, 2018. PMID: 30100279. DOI: 10.1016/j.jbmt.2017.09.017

19 Ottawa panel evidence-based clinical practice guidelines for therapeutic exercises and manual therapy in the management of osteoarthritis. Phys Ther 85(9): 907-971, 2005. PMID: 16117601.

20 Jansen MJ, Viechtbauer W, Lenssen AF, Hendriks EJ and de Bie RA: Strength training alone, exercise therapy alone, and exercise therapy with passive manual mobilisation each reduce pain and disability in people with knee osteoarthritis: A systematic review. J Physiother 57(1): 11-20, 2011. PMID: 21402325. DOI: $10.1016 /$ S1836-9553(11)70002-9 
21 Vermeulen HM, Obermann WR, Burger BJ, Kok GJ, Rozing PM and van Den Ende CH: End-range mobilization techniques in adhesive capsulitis of the shoulder joint: A multiple-subject case report. Phys Ther 80(12): 1204-1213, 2000. PMID: 11087307.

22 Lin HT, Hsu AT, An KN, Chang Chien JR, Kuan TS and Chang GL: Reliability of stiffness measured in glenohumeral joint and its application to assess the effect of end-range mobilization in subjects with adhesive capsulitis. Man Ther 13(4): 307-316, 2008. PMID: 17936055. DOI: 10.1016/j.math.2007.02.003

23 E L, Pecos-Martín D, Domenech-García V, Herrero P and Gallego-Izquierdo T: Effects of an anteroposterior mobilization of the glenohumeral joint in overhead athletes with chronic shoulder pain: A randomized controlled trial. Musculoskelet Sci Pract 38: 91-98, 2018. PMID: 30359870. DOI: 10.1016/j.msksp. 2018.09.009

24 Altman R, Asch E, Bloch D, Bole G, Borenstein D, Brandt K, Christy W, Cooke TD, Greenwald R and Hochberg M: Development of criteria for the classification and reporting of osteoarthritis. Classification of osteoarthritis of the knee. Diagnostic and therapeutic criteria committee of the American rheumatism association. Arthritis Rheum 29(8): 1039-1049, 1986. PMID: 3741515. DOI: 10.1002/art.1780290816

25 Altman RD, Fries JF, Bloch DA, Carstens J, Cooke TD, Genant H, Gofton P, Groth H, McShane DJ and Murphy WA: Radiographic assessment of progression in osteoarthritis. Arthritis Rheum 30(11): 1214-1225, 1987. PMID: 3689459. DOI: $10.1002 /$ art 1780301103

26 Edmond SL: Joint mobilization/manipulation: Extremity and Spinal Techniques. $2^{\text {nd }}$ edition, 1 st volume. St. Louis, Mosby Elsevier, pp. 57, 2006.

27 Huskisson EC: Visual analogue scales. In: Pain measurement and assessment. Melzack R (ed). New York, Raven, pp. 33-37, 1983.

28 Norkin CC and White DJ: Measurement of joint motion: A guide to goniometry. 4 th edition, $1^{\text {st }}$ volume. Philadelphia, FA Davis Company, pp. 64-67, 2009.

29 Hoppenfeld S: Physical Examination of the Spine and Extremities. 1st edition, $1^{\text {st }}$ volume. Wellington, Prentince Hall, pp. 187, 1976.

30 Stark T, Walker B, Phillips JK, Fejer R and Beck R: Hand-held dynamometry correlation with the gold standard isokinetic dynamometry: A systematic review. PM R 3(5): 472-479, 2011. PMID: 21570036. DOI: 10.1016/j.pmrj.2010.10.025

31 Podsiadlo D and Richardson S: The timed "Up \& Go": A test of basic functional mobility for frail elderly persons. J Am Geriatr Soc 39(2): 142-148, 1991. PMID: 1991946. DOI: 10.1111/ j.1532-5415.1991.tb01616.x

32 Rikli R and Jones C: The reliability and validity of a 6-minute walk test as a measure of physical endurance in older adults. Journal of Aging and Physical Activity 6(4): 363-375, 2019. DOI: $10.1123 /$ japa.6.4.363

33 Mangus B, Hoffman L, Hoffman M and Altenburger P: Basic principles of extremity joint mobilization using a kaltenborn approach. Journal of Sport Rehabilitation 11(4): 235-250, 2019. DOI: 10.1123/jsr.11.4.235

34 Schmid A, Brunner F, Wright A and Bachmann LM: Paradigm shift in manual therapy? Evidence for a central nervous system component in the response to passive cervical joint mobilisation. Man Ther 13(5): 387-396, 2008. PMID: 18316238. DOI: 10.1016/j.math.2007.12.007
35 Lundberg A, Malmgren K and Schomburg ED: Role of joint afferents in motor control exemplified by effects on reflex pathways from Ib afferents. J Physiol 284: 327-343, 1978. PMID: 215758. DOI: 10.1113/jphysiol.1978.sp012543

36 Frank C, Akeson WH, Woo SL, Amiel D and Coutts RD: Physiology and therapeutic value of passive joint motion. Clin Orthop Relat Res (185): 113-125, 1984. PMID: 6705368.

37 Zusman M: Spinal manipulative therapy: Review of some proposed mechanisms, and a new hypothesis. Aust J Physiother 32(2): 89-99, 1986. PMID: 25026443. DOI: 10.1016/S00049514(14)60645-0

38 Hing W, Hall T, Rivett D, Vicenzino B and Mulligan B: The mulligan concept of manual therapy: Textbook of techniques. $1^{\text {st }}$ edition, $1^{\text {st }}$ volume. London, Churchill Livingstone, pp. 67, 2015.

39 Capin JJ and Snyder-Mackler L: The current management of patients with patellofemoral pain from the physical therapist's perspective. Ann Jt 3:40, 2018. PMID: 31414069. DOI: 10.21037/aoj.2018.04.11

40 Page P, Frank CC and Lardner R: Assessment and Treatment of Muscle Imbalance: The Janda Approach. $1^{\text {st }}$ edition, $1^{\text {st }}$ volume. Stanningley, Human Kinetics, pp. 184, 2010.

41 Warmerdam A: Arthrokinematic Therapy: Improving Muscle Performance through Joint Manipulation. $1^{\text {st }}$ edition, $1^{\text {st }}$ volume. New York, Pine Publications, pp. 32-44, 1999.

42 Wyke BD: Articular neurology. In: Aspects of Manipulative Therapy. Glasgow EF, Twoney LT, Scull ER, Kleynhams AM (eds). New York, Churchill Livingstone, pp. 72-77, 1985.

43 Ko T, Lee S and Lee D: Manual therapy and exercise for OA knee: Effects on muscle strength, proprioception, and functional performance. Journal of Physical Therapy Science 21(4): 293299, 2020. DOI: 10.1589/jpts.21.293

44 Kappetijn O, van Trijffel E and Lucas C: Efficacy of passive extension mobilization in addition to exercise in the osteoarthritic knee: An observational parallel-group study. Knee 21(3): 703-709, 2014. PMID: 24746916. DOI: 10.1016/ j.knee.2014.03.003

45 Reinke $\mathrm{H}$ and Dinse HR: Functional characterization of cutaneous mechanoreceptor properties in aged rats. Neurosci Lett 216(3): 171-174, 1996. PMID: 8897485. DOI: 10.1016/ 0304-3940(96)13039-1

46 Frigo $\mathrm{C}$, Wyss $\mathrm{C}$ and Brunner R: The effects of the rectus femoris muscle on knee and foot kinematics during the swing phase of normal walking. Applied Sciences 10(21): 7881, 2020. DOI: $10.3390 /$ app10217881

47 Reinbolt JA, Fox MD, Arnold AS, Ounpuu S and Delp SL: Importance of preswing rectus femoris activity in stiff-knee gait. J Biomech 41(11): 2362-2369, 2008. PMID: 18617180. DOI: 10.1016/j.jbiomech.2008.05.030 